\title{
Peritoneal Dialysis: A Primary Care Perspective
}

\author{
Ramesh Saxena, MD, PhD, and Cheryl West, RN, BSN
}

As the population of chronic kidney disease (CKD) and end-stage renal disease (ESRD) grows at an alarming rate, primary care physicians will increasingly be involved in the management of these patients. Early recognition of CKD and timely referral to a nephrologist when glomerular filtration rate approaches $30 \mathrm{~mL} / \mathrm{min} / 1.73 \mathrm{~m}^{2}$ is extremely important to improve ESRD outcome and appropriate selection of dialysis modality. Peritoneal dialysis (PD) remains a viable treatment option for ESRD patients. PD is less expensive dialysis modality and may provide a survival advantages over hemodialysis in first 2 to 4 years of treatment. Preserving residual renal function (RRF) is of paramount importance to prolong the survival outcomes in PD patients. Thus preservation of RRF is an important goal in the management of PD patients. Every effort should be made to avoid nephrotoxic drugs like aminoglycosides and nonsteroidal anti-inflammatory drugs, and limit the use of radiocontrast agents in PD patients with RRF. Judicious use of prophylactic antibiotics to prevent peritonitis would further help to reduce morbidity from PD. Protecting peritoneal membrane from long-term toxic and metabolic effects of the conventional glucose-based solutions is another objective to further improve PD outcome. Development of new, more biocompatible PD solutions holds promise for the future. One such solution, icodextrin, is now approved for use in the United States. Although extremely safe to use, it is associated with unique metabolic effects that may concern primary care physicians. They include false elevation of blood glucose, a reversible increase in serum alkaline phosphatase and a false decline in serum amylase. Monitoring of glycemia by assays that use glucose dehydrogenase pyrroloquinoline quinone enzymes should be avoided and serum amylase alone should not be relied on in diagnosing pancreatitis in patients on icodextrin. (J Am Board Fam Med 2006;19:380-9.)

Recent years have seen an explosive growth of endstage renal disease (ESRD) population in the United States. There were over 400,000 ESRD patients in 2001, consuming $7 \%$ of the Medicare budget and $\$ 23$ billion in total costs. ${ }^{1}$ The ESRD population is projected to grow to 650,000 by 2010 (Figure 1). ${ }^{1}$ Rising ESRD population is just a small tip of the large chronic kidney disease (CKD) iceberg. For each patient with ESRD, there are over 100 patients with various stages of $\mathrm{CKD} .^{2,3}$ In the

Submitted 22 September 2005; revised 21 December 2005; accepted 19 January 2006.

From the Department of Internal Medicine, Division of Nephrology (RS), University of Texas, Southwestern Medical Center; and University of Texas Southwestern Peritoneal Dialysis Program (CW), Dallas.

Conflict of interest: none declared.

Corresponding author: Ramesh Saxena, $\mathrm{MD}, \mathrm{PhD}$, Assistant Professor, Director of the University of Texas Southwestern Peritoneal Dialysis Program, Department of Internal Medicine, Division of Nephrology, University of Texas, Southwestern Medical Center, 5323 Harry Hines Boulevard, H5:122, Dallas, TX 75390-8856 (E-mail: Ramesh.saxena@utsouthwestern.edu). wake of rising CKD population, the Kidney Disease Outcome Qualitative Initiative (KDOQI) published clinical practice guidelines in 2002. ${ }^{3}$ KDOQI recommends classifying $\mathrm{CKD}$ into 5 stages based on the glomerular filtration rate. ${ }^{3}$ Furthermore, KDOQI recommends early diagnosis and treatment of CKD by the primary care physicians in collaboration with nephrologist to reduce morbidity and mortality and delay the progression of CKD. Moreover, it recommends timely referral to nephrologist when estimated glomerular filtration rate (eGFR) is less than $30 \mathrm{~mL} / \mathrm{min} / 1.73 \mathrm{~m}^{2}$, so that patients can receive proper pre-ESRD education and be well prepared for appropriate renal replacement therapy. ${ }^{3}$ Current treatment options for ESRD include renal transplant, hemodialysis (HD) [mainly in-center HD, but also nocturnal $\mathrm{HD}$ and home $\mathrm{HD}]$ and peritoneal dialysis (PD). Although renal transplant remains the treatment of choice, the proportion of ESRD patients receiving renal transplant has not much changed (Figure 2). ${ }^{1}$ Thus most ESRD patients stay on dialysis. With a 


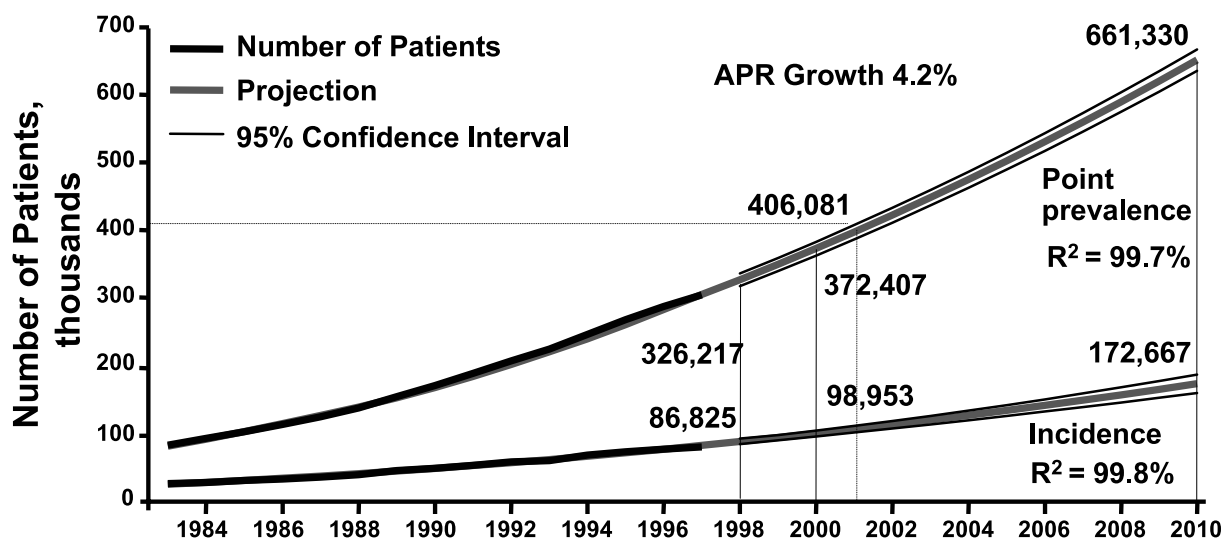

Figure 1. The rising tide of end-stage renal disease (ESRD) patients. Projection of incident and point-prevalent ESRD patients for the year 2010. There has been a steady increase in the incidence of ESRD in the US population since 1980 with a tremendous increase in the expenditure. The prevalence of ESRD is projected to increase by $77 \%$ from 2000 to $2010{ }^{1}$

growing ESRD population, primary care physicians will be increasingly involved in co-managing these patients. A basic knowledge of renal replacement therapies is essential for appropriate management of such patients. PD is a viable dialysis modality, which continues to evolve since inception in the late seventies. In this article, we will review various aspects of $\mathrm{PD}$ from primary care perspective.

\section{Overview of PD}

$\mathrm{PD}$ is achieved by instilling dialysis solution into the peritoneal cavity using a percutaneous abdominal catheter. Water and solutes are exchanged between the capillary blood and the intraperitoneal dialysate across the peritoneum, comprising vascular endothelium, its basement membrane, underlying connective tissue interstitium and a mesothelial monolayer. ${ }^{4}$ Peritoneum has a surface area of 1 to $2 \mathrm{~m}^{2}$ and covers the inner surface of the abdominal wall (parietal peritoneum) and most visceral organs (visceral peritoneum). Only a third of the peritoneum, mainly the parietal peritoneum, is in effective contact with the dialysate and participates in solute and water exchange. ${ }^{5}$

A variety of indwelling silastic and polyurethane catheters are available for PD. ${ }^{6}$ The catheter can be placed laparoscopically or by open surgical technique. A double cuff catheter with an arcuate subcutaneous tunnel and a caudad-oriented exit is recommended. ${ }^{6} \mathrm{PD}$ is ideal for patients with an active lifestyle. There are few contraindications of PD (Table 1).

\section{Peritoneal Dialysis Fluids}

Conventional PD fluids consist of a physiologic solution of electrolytes, a bicarbonate precursor (usually lactate) and glucose in various concentrations $(1.5 \%, 2.5 \%, 4.25 \%)$ as an osmotic agent (Table 2). Glucose is widely accepted as an osmotic agent for PD because it is inexpensive and is considered relatively safe (at least until recently). One disadvantage is its small size. Consequently, it is rapidly absorbed into blood with progressive loss of the osmotic gradient and long-term metabolic consequences.

\section{Peritoneal Dialysis Schedules}

PD can be done manually or can be done with automated devices (Figure 3). It can be continuous (fluid in the abdominal cavity 24 hours a day) or intermittent (when abdominal cavity is dry for a part of the day). The intermittent schedules are used in patients with considerable residual renal functions. The various schedules for peritoneal dialysis are as follows:

- Manual

-Continuous ambulatory peritoneal dialysis (CAPD)

- Automated peritoneal dialysis (APD)

-Continuous cycler-assisted peritoneal dialysis (CCPD)

-Nocturnal intermittent peritoneal dialysis (NIPD)

-CAPD with a single nocturnal exchange using a nocturnal assist devise 


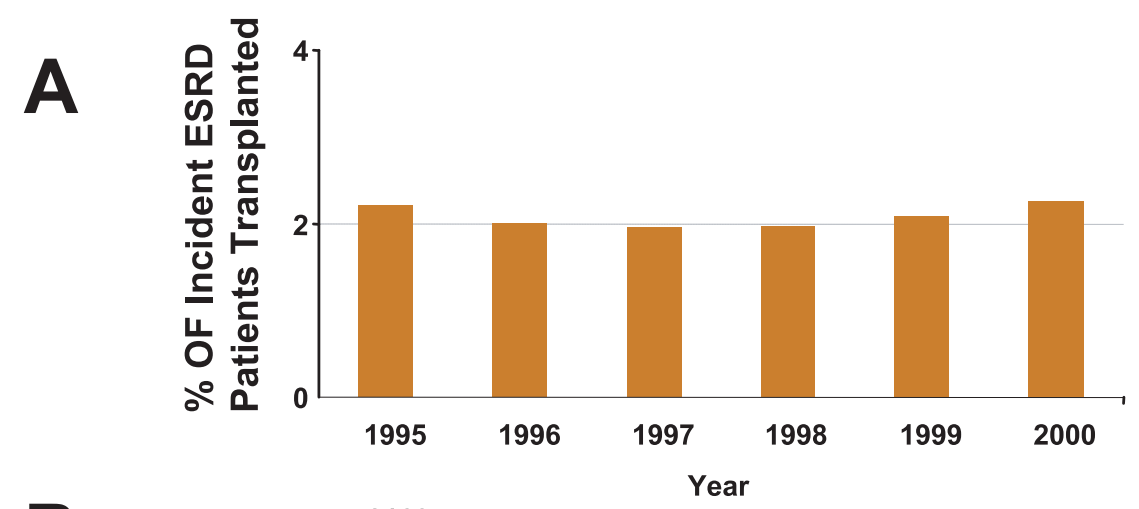

B
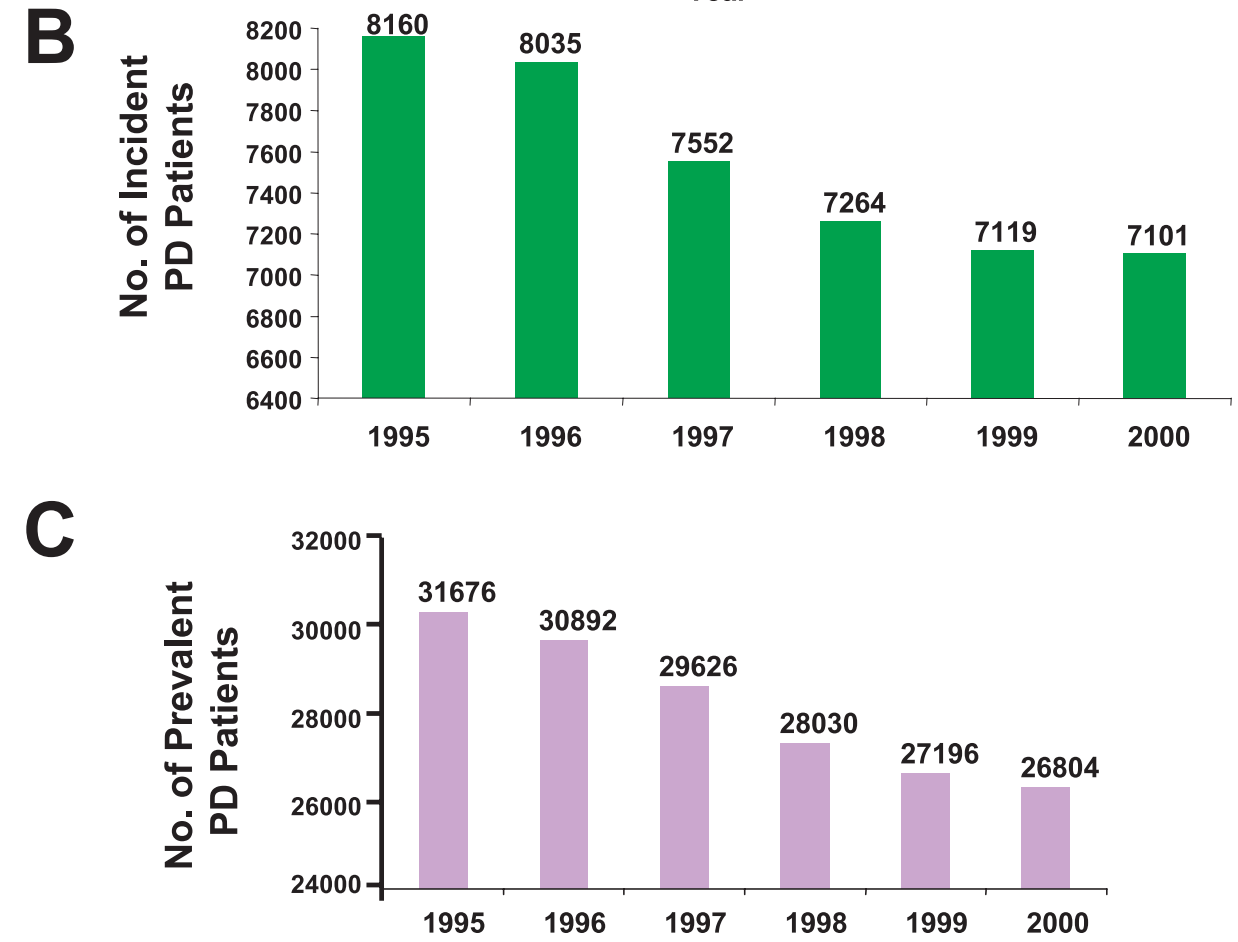

Figure 2. Growth of various renal replacement therapies. Whereas the end-stage renal disease (ESRD) patient population is growing steadily, the growth of various renal replacement therapies is disproportional. Although there is a steady growth of hemodialysis population, the proportion of incident ESRD patients receiving kidney transplant has remained constant at approximately 2\% (A). On the other hand, the number of incident ESRD patients receiving peritoneal dialysis (PD) has progressively declined since 1995 (B) such that the prevalent PD population has decreased by $15 \%$ since $1995(\mathrm{C}){ }^{1}$

\section{CAPD}

This requires only connecting tubes and bags of solutions ( 2 to $3 \mathrm{~L}$ ) using gravity to fill and empty the peritoneal cavity. The most commonly used method employs 4 exchanges per day of 2-L bags, but in some patients, especially those who are anuric and have a high body mass index (BMI), 5 exchanges and/or larger sized bags ( 2.5 or $3 \mathrm{~L}$ ) are necessary to increase clearance. A few patients (low $\mathrm{BMI}$, excellent residual renal functions) may re- quire only 3 exchanges per day, but this is inadequate in the majority of patients with ESRD. The night dwell in CAPD is long (8 to 10 hours). Sometimes, enhancement of solute removal with CAPD can be accomplished by performing additional 1 to 2 nocturnal exchanges using nighttime assist device such as Quantum device (Baxter) or a mini-cycler (Fresenius). Patients monitor their daily weights and adjust the glucose concentration of the dialysate based on volume status. Typically, higher glu- 
Table 1. Contraindications to Peritoneal Dialysis

Absolute
Peritoneal adhesions
Encapsulating peritoneal sclerosis
Pleuro-peritoneal leak
Relative (major)
Psychosis*
Mental retardation*
Quadreplegia/ hemiplegia*
Other physical handicap*
Blindness
Colostomy/gastrostomy
Poor motivation
Relative (minor)
Obesity
Hernia
Polycystic kidneys
Low back problems

${ }^{*}$ Will need assistance. Contraindicated for self-treatment.

cose solutions $(2.5 \%$ and $4.25 \%)$ are used in volume-overloaded states to promote greater ultrafiltration.

\section{CCPD}

In this technique, the patient loads the bags of solutions on to a cycler and connects the catheter to the cycler at bedtime. The cycler is programmed to do 3 to 5 (or more) exchanges during the night. In the morning, 2 to $2.5 \mathrm{~L}$ of fluid is left in the abdomen for the long daytime dwell (14 to 16 hours). Occasionally, an additional exchange is done during the day to improve clearance or ultrafiltration. CCPD is becoming increasingly popular in the United States. ${ }^{1}$

Table 2. Composition of Peritoneal Dialysis Fluids

\begin{tabular}{lcc}
\hline & Conventional & Icodextrin \\
\hline Dextrose $(\mathrm{g} / \mathrm{dL})$ & $1.5,2.5,4.25$ & 0 \\
Icodextrin $(\mathrm{g} / \mathrm{dL})$ & 0 & 7.5 \\
Sodium $(\mathrm{mmol} / \mathrm{L})$ & 132.0 & 132.0 \\
Chloride $(\mathrm{mmol} / \mathrm{L})$ & 102.0 & 96.0 \\
Calcium $(\mathrm{mEq} / \mathrm{L})$ & 2.5 to 3.5 & 3.5 \\
Magnesium $(\mathrm{mEq} / \mathrm{L})$ & 0.5 to 1.5 & 0.5 \\
Lactate $(\mathrm{mEq} / \mathrm{L})$ & 40.0 & 40.0 \\
Bicarbonate $(\mathrm{mmol} / \mathrm{L})$ & 0 & 0 \\
Osmolality $(\mathrm{mOsm} / \mathrm{kg})$ & 346 to 485 & 282 to 286 \\
$\mathrm{pH}$ & 5.2 & 5.2 \\
\hline
\end{tabular}

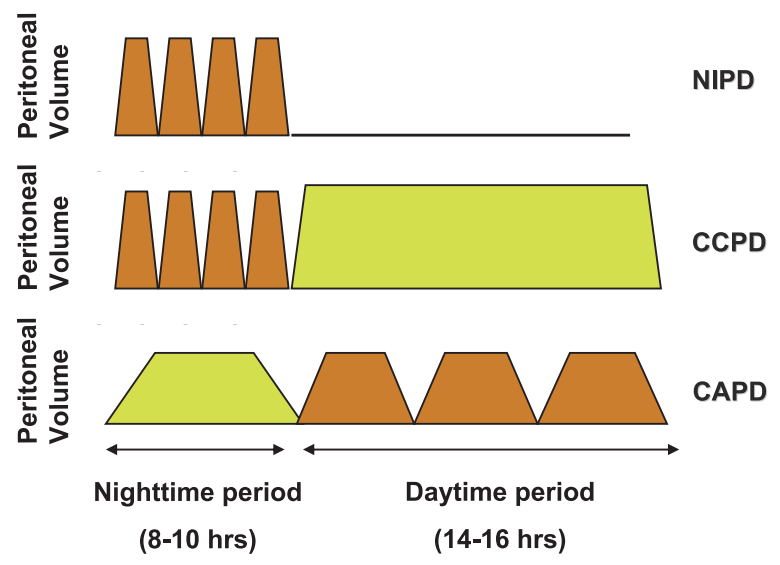

Figure 3. Various peritoneal dialysis (PD) schedules. NIPD, nocturnal intermittent PD; CCPD, continuous cycler-assisted PD; CAPD, continuous ambulatory PD.

NIPD

NIPD is a cycler-assisted nightly procedure as described above except that the peritoneal cavity is left empty during the day. It is usually offered to patients with excellent residual renal function.

\section{Physiology of Peritoneal Dialysis}

In PD, the solute and water transport across the peritoneum occurs by diffusion and convection (ultrafiltration) through a system of pores of variable diameters (Figure 4). ${ }^{7,8}$ The peritoneal permeability to small solutes is investigated by peritoneal equilibration test (PET), and the peritoneum is classified into 4 transport categories: low, low average, high average, and high. ${ }^{9}$ PET results are used to design PD regimen for individual patients.

Ultrafiltration is achieved by using hypertonic glucose to create crystalloid osmotic pressure gradient between dialysate and blood. ${ }^{10}$ Approximately $60 \%$ of the instilled glucose is absorbed into blood during a 4-hour dwell.

\section{Pros and Cons of Peritoneal Dialysis}

PD has several advantages as well as limitations (Table 3). PD is less expensive than HD (Figure 5). ${ }^{11}$ Unlike saw-tooth treatment with $\mathrm{HD}, \mathrm{PD}$ delivers steady-state treatment avoiding wide fluctuation of plasma volume and solutes and is generally better tolerated by the patients with cardiovascular compromise. In addition, PD provides flexible schedules (unlike fixed HD shifts), thus bestowing opportunities to work, travel, and par- 


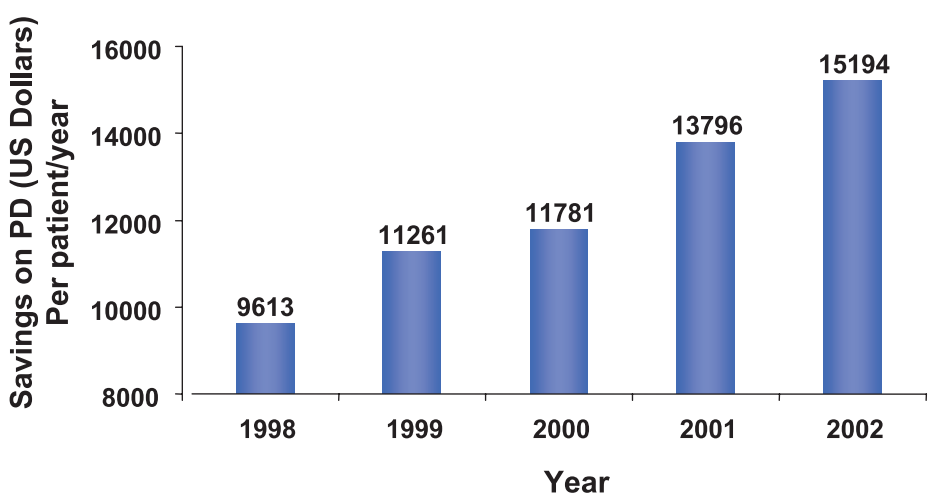

Figure 4. Three-pore model of the peritoneal membrane. Although various models of peritoneal membrane have been proposed, the 3-pore model is most widely accepted to explain solute and water transport across the peritoneum. It assumes the capillary endothelium to be the major barrier to solute and water transport, which ensues through a system of pores that are classified into 3 broad categories, ultrasmall, small, and large pores. The abundant small pores (40 to $60 \mathrm{~A}$ radii) are the tortuous intercellular clefts between the endothelial cells. They are responsible for small solute transport. The ultrasmall pores (radius 3 to $5 \AA$ ), also present in large number, are probably the transendothelial aquaporin-1. Solute free water transport occurs across them. In addition, a few large pores ( 200 to $300 \AA$ radii) are present. The nature of the large pores is not well known. Macromolecules like albumin are transported across them.

ticipate in daytime activities for patients. PD being needleless, alleviates the anxiety experienced by HD patients from needle sticks, helps to preserve arteriovenous access sites for future $\mathrm{HD}$, and minimizes risks of acquiring blood-borne infections like hepatitis C. ${ }^{12,13}$ In addition, PD facilitates

Table 3. Pros and Cons of Peritoneal Dialysis

\begin{tabular}{l} 
Pros \\
Lower cost than hemodialysis (HD) \\
Patients more satisfied with overall care compared with HD \\
Steady-state treatment. Better tolerated hemodynamically \\
Flexible schedules \\
Needleless \\
Preservation of vascular sites for future hemodialysis \\
Lower risk of blood-borne infections ${ }^{12,13}$ \\
Alleviates anxiety from needle sticks \\
Better preservation of residual renal function \\
Fewer diet and fluid restrictions \\
Cons \\
Continuous therapy. No days off. Leads to patient and \\
family burnout \\
Body image concerns because of presence of catheter and \\
fluid in the abdomen \\
High technique failure rate compared with HD \\
Space needed for monthly supplies of dialysis equipment/ \\
solutions \\
Inability to lift $>25$ lbs. \\
Non-compliance with dialysis can lead to complications \\
such as infections, uremia, and technique failure \\
\hline
\end{tabular}

preservation of residual renal function (RRF) better than HD. ${ }^{14} \mathrm{PD}$ may also contribute to superior allograft function in the postoperative period following a kidney transplant. ${ }^{15}$

Despite aforesaid benefits, there are several drawbacks of PD (Table 3). PD, being a continuous therapy with no "off" days, may be inconvenient and can cause fatigue and burnout of patients and families. Some patients may have concern with body image resulting from the presence of a catheter and fluid in the abdomen. Moreover there are

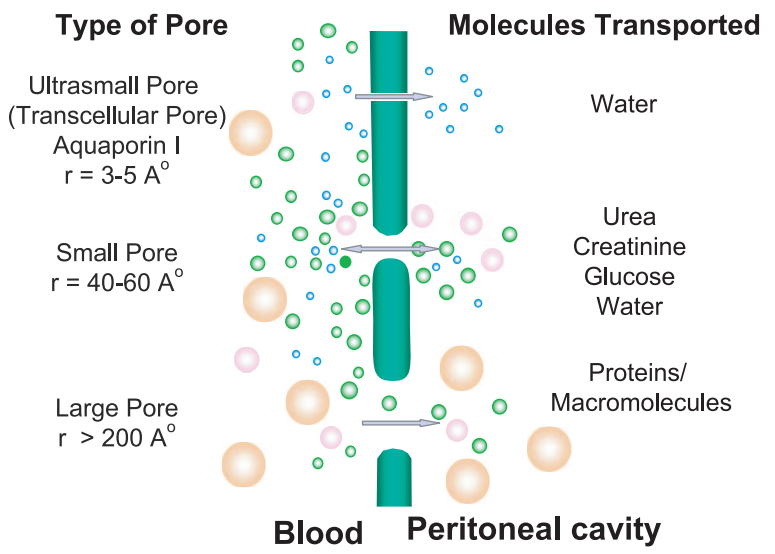

Figure 5. Cost savings on peritoneal dialysis (PD). Medicare savings on PD per patient per year have progressively increased over the years. ${ }^{11}$ 
Table 4. Complications of Peritoneal Dialysis

\begin{tabular}{l}
\hline Infections \\
Peritonitis \\
Tunnel infections \\
Exit site infections \\
Associated with increased intra-abdominal pressure \\
Hernia \\
Abdominal wall edema \\
Scrotal/vulvar edema/hydrocele \\
Hydrothorax \\
Mechanical \\
Catheter leakage \\
Catheter tip migration \\
Inadequate drainage \\
Metabolic \\
Hyperglycemia \\
Hyperlipidemia \\
Obesity \\
Protein loss \\
Hypokalemia \\
Hypomagnesemia \\
Miscellaneous \\
Encapsulating peritoneal sclerosis \\
Eosinophilic peritonitis \\
\hline
\end{tabular}

various complications associated with PD (Table 4). They are described briefly in the following section.

\section{Complications Associated with Peritoneal Dialysis}

Infections are the most important group of complications and include exit site and tunnel infections, and peritonitis. As connection between the dialysate bag and the PD catheter is broken 2 to 5 times a day, even the most meticulous aseptic technique cannot provide absolute sterility. Infections may also result from endogenous bowel sources. Thus peritonitis remains the most important complication and a leading cause of hospitalization and technique failure. ${ }^{16}$ Despite significant improvement in the incidence, peritonitis rates of $>0.5$ episodes per patient per year are still common. ${ }^{16}$ Peritonitis presents with abdominal pain, fever, and cloudy dialysate containing more than 100 white cells $/ \mathrm{mm}^{3}$ with greater than $50 \%$ polymorphonuclear leukocytes. ${ }^{17}$ Most cases of peritonitis can be treated on an out-patient basis by intraperitoneal antibiotics. ${ }^{17}$ Antibiotic prophylaxis before dental, endoscopic, and gynecological procedures, and drainage of the abdomen before abdominal and pelvic procedures is recommended to reduce risk of peritonitis (Table 5). ${ }^{17,18}$

Increased intra-abdominal pressure can predispose to hernias, hydrocele, genital edema, and rarely hydrothorax from pleuro-peritoneal communication. ${ }^{19}$ In addition, mechanical complications

Table 5. Prophylactic Antibiotics in Patients on Peritoneal Dialysis

\begin{tabular}{|c|c|c|}
\hline Condition & Drug & Adult Dose \\
\hline \multicolumn{3}{|l|}{$\begin{array}{l}\text { Prophylactic regimen for dental, oral, } \\
\text { or upper respiratory procedures }\end{array}$} \\
\hline Standard regimen & Amoxicillin & $\begin{array}{l}2 \mathrm{~g} \text { orally (po, per os) } 1 \text { hour before } \\
\text { procedure }\end{array}$ \\
\hline Penicillin allergy & $\begin{array}{l}\text { Clindamycin, Cephalexin, Cefadroxil, } \\
\text { Azithromycin, or Clarithromycin }\end{array}$ & $\begin{array}{l}600 \mathrm{mg} \text { po } 1 \text { hour before procedure; } 2 \mathrm{~g} \\
\text { po } 1 \text { hour before procedure; } 500 \mathrm{mg} \text { po } \\
1 \text { hour before procedure }\end{array}$ \\
\hline $\begin{array}{l}\text { Patients unable to take oral } \\
\text { medication }\end{array}$ & Ampicillin & $2 \mathrm{~g}$ IV/IM 30 minutes before procedure \\
\hline $\begin{array}{l}\text { Penicillin allergy and cannot take } \\
\text { oral medications }\end{array}$ & Clindamycin or Cefazolin & $\begin{array}{l}600 \mathrm{mg} \text { IV } 30 \text { minutes before procedure; } 1 \\
\text { g IV/IM } 30 \text { minutes before procedure }\end{array}$ \\
\hline \multicolumn{3}{|c|}{ Prophylactic regimen for genitourinary/gastrointestinal (excluding esophageal) procedures } \\
\hline Standard regimen & $\begin{array}{l}\text { Ampicillin and Gentamycin plus Amoxicillin } \\
\text { or Ampicillin }\end{array}$ & $\begin{array}{l}2 \mathrm{~g} \mathrm{IM} / \mathrm{IV} 30 \text { minutes before procedure; } \\
1.5 \mathrm{mg} / \mathrm{kg} \text { (maximum } 120 \mathrm{mg} \text { ) IM/IV } 30 \\
\text { minutes before procedure; } 1 \mathrm{~g} \text { po } 6 \\
\text { hours after the initial dose; } 1 \mathrm{~g} \mathrm{IM} / \mathrm{IV} 6 \\
\text { hours after the initial dose }\end{array}$ \\
\hline Patients allergic to penicillins & Vancomycin Plus gentamycin & $\begin{array}{l}1 \mathrm{~g} \mathrm{IV} \text { over } 1 \text { to } 2 \text { hours completing } \\
\text { within } 30 \text { minutes of the starting } \\
\text { procedure; } 1.5 \mathrm{mg} / \mathrm{kg} \text { (maximum } 120 \\
\mathrm{mg} \text { ) IM/IV } 30 \text { minutes before procedure }\end{array}$ \\
\hline
\end{tabular}

$\mathrm{IV}$, intravenously; IM, intramuscularly. 
of catheters such as malfunction, migration, or kinks can also occur. ${ }^{19}$

Other complications include dialysate protein loss and metabolic complications from glucose absorption such as hyperglycemia, hypertriglyceridemia, or weight gain. Insulin can be added to dialysate for tighter glycemic control $\left({ }^{20-22}\right)$.

\section{Importance of Residual Renal Function in Peritoneal Dialysis}

The RRF progressively declines in virtually all patients, both before and after initiation of dialysis. However, RRF declines faster in HD than in PD. ${ }^{14}$ It is widely recognized that RRF is directly related to dialysis adequacy, conserved endocrine function, enhanced middle molecule clearance, better volume and blood-pressure control and superior cardiovascular and survival outcomes. ${ }^{23,24}$ Thus preservation of RRF is an important goal in the management of PD patients. Every effort should be made to avoid nephrotoxic drugs like aminoglycosides and nonsteroidal anti-inflammatory drugs, and limit the use of radiocontrast agents in PD patients with RRF. ${ }^{25}$ Use of angiotensin-converting enzyme inhibitors (or angiotensin receptor blockers) may help to preserve $\mathrm{RRF}^{26}$

\section{The Status for Peritoneal Dialysis in the United States}

Contemporary data suggest that overall mortality is at least similar in the HD and the PD population $\left({ }^{27-30}\right)$. Whereas some studies show that PD may offer survival benefit over HD in the first few years of the treatment $\left({ }^{27-30}\right)$, others demonstrate no survival advantage or higher mortality risk in selected PD patients. ${ }^{31,32}$ There may be a higher risk of mortality in PD patients with coronary artery disease and congestive heart failure particularly among elderly diabetic patients with comorbidities. ${ }^{30,33,34}$ However, PD patients regard their care much better than HD patients. A recent study showed that PD patients were more satisfied with their care than HD patients and rated their care higher in all the 23 items investigated. ${ }^{35}$

Despite the aforesaid benefits, utilization of PD in the United States has progressively diminished. Only $8.8 \%$ of total US dialysis patients were receiving PD in 2001 (Figure 6). ${ }^{1}$ In contrast, PD is used much more frequently elsewhere in the world (Figure 6). ${ }^{1}$ The reasons for lower PD utilization in the United States are influenced by psychosocial and economic factors, physician bias and education as well as inadequate pre-ESRD patient education. ${ }^{36}$ First, many US training programs either do not have an appropriate number of PD patients or allocate sufficient time for PD training to the fellows. ${ }^{37}$ A practicing nephrologist with inadequate PD training will be reluctant to offer this therapy to the patients. Another contributing factor is late patient referral to the nephrologists. KDOQI recommends primary care physicians to refer the patients to nephrologists when they approach stage 4 CKD (eGFR $\left.<30 \mathrm{~mL} / \mathrm{min} / 1.73 \mathrm{~m}^{2}\right){ }^{3}$ At present, late referral to a nephrologist is quite common and has a negative impact on patient outcome. In addition, it results in poor PD enrollment. ${ }^{36,38,39} \mathrm{~Pa}$ tients referred earlier and seen more frequently by a nephrologist have a chance to receive pre-ESRD counseling and actively participate in the decision making. The importance of patient education is further underscored by preliminary results of the National Pre-ESRD Education Initiative. ${ }^{40}$ When given pre-ESRD education, more than a third of the CKD patients started on PD. ${ }^{40}$ Thus timely referral to nephrologist is extremely important to the provision of appropriate pre-ESRD care, increased PD utilization and improvement of overall ESRD outcomes in the United States.

\section{Current Problems with Peritoneal Dialysis}

PD may prove superior to HD in selected patients. Improved survival is, however, limited to the first 2 to 4 years, and the majority of patients shift to HD because of technique failure. ${ }^{41,42}$ The PD technique survival is $30 \%$ to $50 \%$ at 5 years and is less than $20 \%$ at 10 years. ${ }^{42}$ Ongoing structural and functional changes of the peritoneal membrane are leading cause of long-term PD failure.

\section{Structural and Functional Changes in the Peritoneum during Peritoneal Dialysis}

Contemporary dialysis solutions are hyperosmolar and acidic ( $\mathrm{pH}$ 5.2) and have high glucose and lactate content. In addition, they contain highly toxic glucose degradation products that are formed during heat sterilization and storage of the dialysate. Long-term exposure of peritoneum to current unphysiologic fluids leads to morphologic changes characterized by mesothelial cell loss, interstitial fibrosis, vasculopathy (similar to diabetic vascu- 


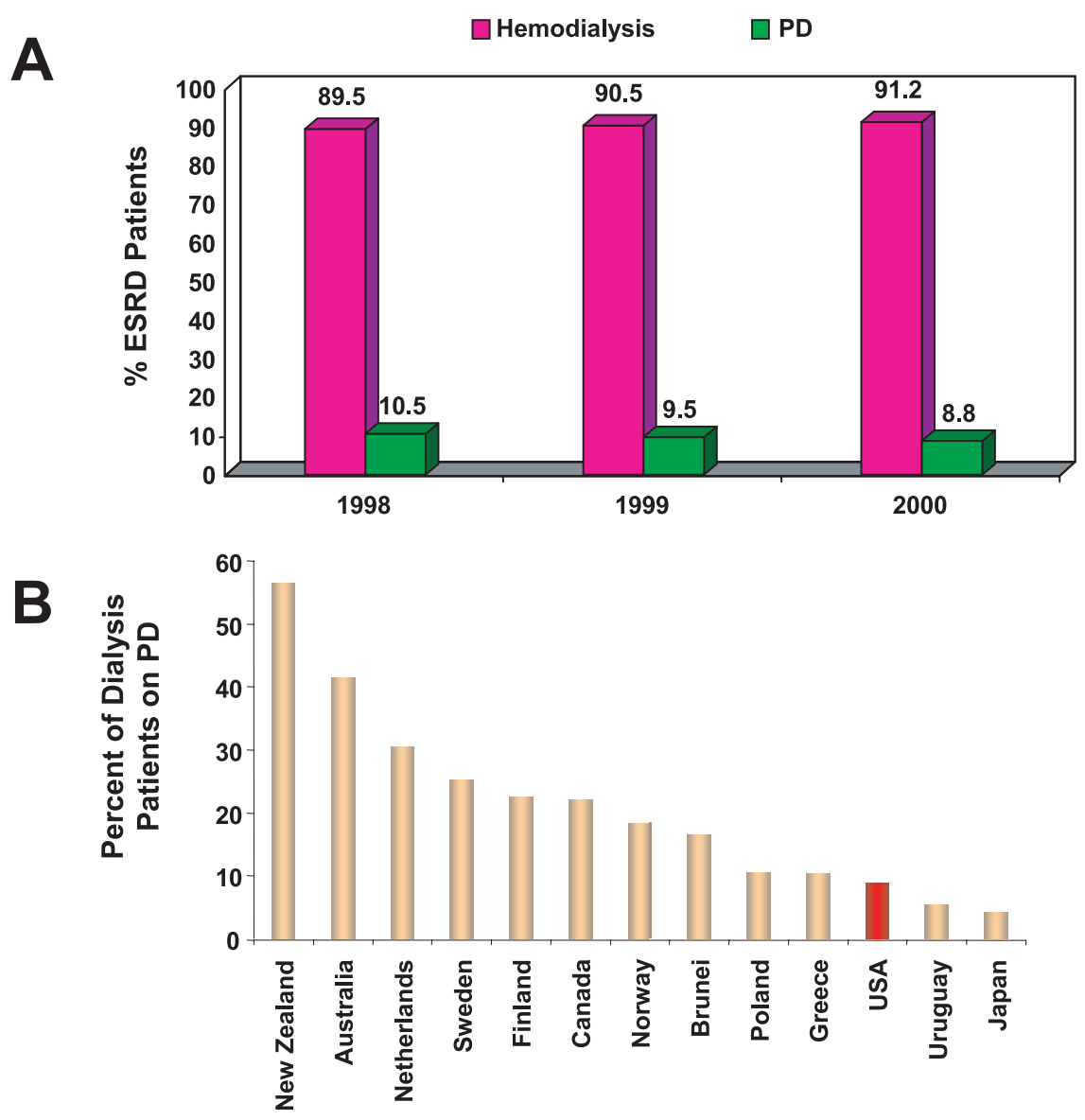

Figure 6. Utilization of peritoneal dialysis (PD) in various countries. Whereas PD is being used less and less in the United States with only $8.8 \%$ of dialysis patients receiving PD in 2000 (A), a much larger proportion of dialysis patients receive $P D$ in most developed countries across the globe (B).

lopathy, even in nondiabetic patients) and neovascularization. ${ }^{43}$ Consequently there is an increase in the peritoneal small solute transport and glucose with progressive loss of ultrafiltration. ${ }^{41}$ This may result in chronic volume overload state, poor solute clearance, rapid glucose absorption, and sizeable protein loss, with a significant impact on both technique and patient survival. ${ }^{41}$

\section{New Solutions for Peritoneal Dialysis}

Three new PD solutions have been recently introduced for clinical use in Europe. They include icodextrin, amino acid solutions, and bicarbonatebuffered solutions. ${ }^{44-48}$ They offer significant improvement in the acute and chronic effects of the conventional glucose-based PD solutions.

Of these new solutions, icodextrin, a large glucose polymer, was recently approved by the FDA for use in high and high-average transport patients (Table 2). ${ }^{44}$ It produces prolonged ultrafiltration at dwell periods of up to 12 hours. Although icodextrin has excellent safety profile, it is associated with several distinctive metabolic effects that may concern primary care physicians.

Icodextrin usage can falsely elevate serum glucose readings when using glucose dehydrogenase pyrroloquinoline quinone (GDH-PQQ)-based assays. ${ }^{49}$ It is recommended that clinicians should refer to the product labeling and avoid GDHPQQ-based glucose monitoring systems in diabetic PD patients on icodextrin.

Icodextrin may cause a decline in serum amylase level because of interference by icodextrin metabolites on amylase assay. ${ }^{44,50}$ It is therefore recommended not to rely on serum amylase alone in diagnosing pancreatitis in patients on icodextrin.

Icodextrin can reversibly increase serum alkaline phosphatase (ALP) due to competitive inhibition of hepatic clearance. ${ }^{44,51}$ Elevated ALP is not associated with any adverse events or abnormality in 
other liver function tests. ALP values rapidly normalize on discontinuation of icodextrin.

\section{Future Prospects}

No single PD solution conforms requirements of an ideal dialysate: effective ultrafiltration, longterm preservation of peritoneal membrane, and correction of nutritional and metabolic abnormalities. However, using the new PD solutions in combination may help to achieve these goals. Moreover, modulation of the molecular pathways involved in peritoneal fibrosis and angiogenesis offers exciting therapeutic strategies to protect the peritoneum against consequences of long-term $\mathrm{PD}$. It remains to be seen if these maneuvers would prove clinically beneficial.

Contributorship: Ramesh Saxena wrote the major portion of the article. Cheryl West contributed Tables 1 to 4 and Figures 1 to 3,5 , and 6 and was involved in drafting and critically reviewing the manuscript.

\section{References}

1. United States Renal Data System, Annual Data Report 2003, National Institutes of Health, National Institute of Diabetes and Digestive and Kidney Diseases, Bethesda, MD

2. Coresh J, Wei GL, McQuillen G, et al. Prevalence of high blood pressure and elevated serum creatinine level in the United States: findings from the third National Health and Nutrition Examination Survey (1988-1994). Arch Intern Med 2001;161:1207-16.

3. National Kidney Foundation. K/DOQI clinical practice guidelines for chronic kidney disease: evaluation, classification and stratification. Kidney disease outcome quality initiative. Am J Kidney Dis 2002;39:S1-246.

4. Nagy JA. Peritoneal morphology and function. Kidney Int 1996;50(Suppl 56):S2-11.

5. Rubin JL, Clawson M, Planch A, Jones Q. Measurements of peritoneal surface area in man and rat. Am J Med Sci 1988;295:435-8.

6. Gokal R, Alexander S, Ash S, et al. Peritoneal catheters and exit site practices toward optimum peritoneal access. 1998 update. Perit Dial Int 1998;18:1133.

7. Waniewski J. Mathematical models for peritoneal transport characteristics. Perit Dial Int 1999;19: S193-201.

8. Rippe B, Stelin G, Haraldsson B. Computer simulations of peritoneal fluid transport in CAPD. Kidney Int 1991;40:315-25.

9. Twardowski ZJ, Nolph KD, Khanna R, et al. Peritoneal equilibration test. Perit Dial Bull 1987;7:13847.
10. Kreidet RT, Lindholm B, Rippe B. Pathophysiology of peritoneal membrane failure. Perit Dial Int 2000; 20(Suppl 4):S22-42.

11. United States Renal Data System, Annual Data Report 2004 (Economic costs of ESRD, Tables K16K20), National Institutes of Health, National Institute of Diabetes and Digestive and Kidney Diseases, Bethesda, MD

12. O'Seaghdha CM, Foley RN. Septicemia, access, cardiovascular disease and death in dialysis patients. Perit Dial Int 2005;25:534-40.

13. Chan TM, Lok AS, Cheng IK. Hepatitis C infection among dialysis patients: a comparison between patients on maintenance hemodialysis and continuous ambulatory peritoneal dialysis. Nephrol Dial Transplant 1991;6:944-7.

14. Jansen MA, Hart AA, Korevaar JC, Dekker FW, Boeschoten EW, Krediet RT. Predictor of rate of decline of residual renal function in incident dialysis patients. Kidney Int 2002;62:1046-53.

15. Bleyer AJ, Burkart JM, Russell GB, Adams PL. Dialysis modality and delayed graft function after cadaveric renal transplantation. J Am Soc Nephrol 1999; 10:154-9.

16. Strippoli GFM, Tong A, Johnson D, Schena F, Craig JC. Catheter-related interventions to prevent peritonitis in peritoneal dialysis: a systemic review of randomized controlled trials. J Am Soc Nephrol 2004;15:2735-46.

17. Pirano B, Bailie GR, Bernardini J, et al. Peritoneal dialysis-related infections recommendations: 2005 update. Perit Dial Int 2005;25:107-31.

18. Dajani AS, Taubert KA, Wilson W, et al. Prevention of bacterial endocarditis. Recommendations by the American Heart Association. JAMA 1997;277:1794801.

19. Bargman JM. Non-infectious complications of peritoneal dialysis. In: Gokal R, Khanna R, Krediet R, Nolph K, editors. Textbook of peritoneal dialysis, 2000, (2nd ed). Dordrecht, The Netherlands: Kluver Academic Publisher; 2000, p. 609-646.

20. Delarue J, Maingourd C, Lamisse F. Glucose oxidation after a peritoneal and an oral glucose load in a dialyzed patients. Kidney Int 1994;45:1147-52.

21. Wheeler DC. Abnormalities of lipoprotein metabolism in CAPD patients. Kidney Int 1996;54(Suppl 56):S41-6.

22. Quellhorst E. Insulin therapy during peritoneal dialysis: Pros and cons of various forms of administration. J Am Soc Nephrol 2002;13:592-6.

23. Bargman JM, Thorpe KE, Churchill DN. Relative contribution of residual renal function and peritoneal clearance of adequacy of dialysis: a reanalysis of the CANUSA study. J Am Soc Nephrol 2001;12: 2158-62.

24. Paniagua R, Amato D, Vonesh E, et al. Effects of increased peritoneal clearances on mortality rates in peritoneal dialysis: ADEMEX, a prospective ran- 
domized controlled trial. J Am Soc Nephrol 2002; 13:1307-20.

25. Singhal MK, Bhaskaran S, Vidgne E. Rate of decline of residual renal function in patients on continuous peritoneal dialysis and factors affecting it. Perit Dial Int 2000;20:429-38.

26. Li PK-T, Chow K-M, Wong TY-H, Leung C-B, Szeto C-C. Effects of an angiotensin-converting enzyme inhibitor on residual renal function in patients receiving peritoneal dialysis. A randomized controlled study. Ann Intern Med 2003;139:105-12.

27. Collins AJ, Hao W, Xia $\mathrm{H}$, et al. Mortality risks of peritoneal dialysis and hemodialysis. Am J Kid Dis 1999;34:1065-74.

28. Fenton SSA, Schaubel DE, Desmeules M, et al. Hemodialysis versus peritoneal dialysis: a comparison of adjusted mortality rates. Am J Kid Dis 1997; 30:334-42.

29. Korevaar JC, Feith GW, Dekker FW, et al. Effect of starting with hemodialysis compared with peritoneal dialysis in patients new on dialysis treatment: a randomized controlled trial. Kidney Int 2003;64:2222-8.

30. Vonesh EF, Snyder JJ, Foley RN, Collins AJ. The differential impact of risk factors on mortality in hemodialysis and peritoneal dialysis. Kidney Int 2004;66:2389-401.

31. Termorshuizen F, Korevaar JC, Dekker FW, Van Manen JG, Boeschoten EW, Krediet RT. Hemodialysis and peritoneal dialysis: comparison of adjusted mortality rates according to the duration of dialysis: analysis of the Netherlands cooperative study on adequacy of dialysis 2. J Am Soc Nephrol 2003;14: 2851-60.

32. Jaar BG, Coresh J, Plantings IC, et al. Comparing the risk for death with peritoneal dialysis and hemodialysis in a national cohort of patients with chronic kidney disease. Ann Intern Med 2005;143:174-83.

33. Ganesh SK, Hulbert-Shearon T, Port FK, Eagle K, Stack AG. Mortality differences by dialysis modality among incident ESRD patients with and without coronary artery disease. J Am Soc Nephrol 2003;14: 415-24.

34. Stack AG, Molony DA, Rahman NS, Dosekun A, Murthy B. Impact of dialysis modality on survival of new ESRD patients with congestive heart failure in the United States. Kidney Int 2003;64:1071-9.

35. Rubin HR, Fink NE, Plantinga LC, Sadler JH, Kliger AS, Powe NR. Patient ratings of dialysis care with peritoneal dialysis vs hemodialysis. JAMA 2004; 291:697-703.

36. Stack AG. Determinants of modality selection among incident dialysis patients: Results from a national study. J Am Soc Nephrol 2002;13:1279-87.

37. Mehrotra R, Blake P, Berman N, Nolph KD. An analysis of dialysis training in the United States and Canada. Am J Kidney Dis 2002;40:152-60.

38. Kinchen KS, Sadler J, Fink N, Brookmeyer R, Klag MJ, Levey AS, Powe NR. The timing of specialist evaluation in chronic kidney disease and mortality. Ann Intern Med 2002;137:479-86.

39. Stack AG. Impact of timing of nephrology referral and pre-ESRD care on mortality risk among new ESRD patients in the United States. Am J Kidney Dis 2003;41:310-8.

40. Golper T. Patient education: can it maximize the success of therapy? Nephrol Dial Transplant 2001; 16(Suppl 7):20-4.

41. Davies S, Phillips L, Griffiths AM, Russell LH, Naish PF, Russell GI. What really happens to people on long-term peritoneal dialysis? Kidney Int 1998; 54:2207-17.

42. Kawaguchi Y, Hasegawa T, Nakayama M, Kubo H, Shigematu T. Issues affecting the longevity of continuous ambulatory peritoneal dialysis. Kidney Int 1997;52(Suppl 62):S105-7.

43. Williams JD, Craig KJ, Ruhland CV, Topley N, Williams GT. The natural course of peritoneal membrane biology during peritoneal dialysis. Kidney Int 2003;64(Suppl 88):S43-9.

44. Wolfson M, Piraino B, Hamburger RJ, Morton R. A randomized controlled trial to evaluate the efficacy and safety of icodextrin in peritoneal dialysis. Am J Kidney Dis 2002;40:1055-65.

45. Wolfson M, Ogrinc F, Mujais S. Review of clinical trial experience with icodextrin. Kidney Int 2002; 62(Suppl 81):S46-52.

46. Lopez EG, Lindholm B, Tranaeus A. Biocompatibility of new peritoneal dialysis solutions: clinical experience. Perit Dial Int 2000;20(Suppl 5):S48-56.

47. Mortier S, Faict D, Schalkwijk CG, Lameire NH, Vriese ASD. Long-term exposure to new peritoneal dialysis solutions: effects on the peritoneal membrane. Kidney Int 2004;66:1257-65.

48. Williams JD, Topley N, Craig KJ, et al. The EuroBalance trial: the effect of a new biocompatible peritoneal dialysis fluid (balance) on peritoneal membrane. Kidney Int 2004;66:408-18.

49. Wens R, Taminne M, Devriendt J, et al. A previously undescribed side effect of icodextrin: Overestimation of glycemia by glucose analyzer. Perit Dial Int 1998;18:603-9.

50. Grzegorzewska AE, Antczak-Jedrzejczak D, Mariak I. Polyglucose dialysis solution influences serum activity of amylase and lipase differentially. Adv Perit Dial 2000;16:113-8.

51. Plum J, Gentile S, Verger C, et al. Efficacy and safety of a $7.5 \%$ icodextrin peritoneal dialysis solution in patients treated with automated peritoneal dialysis. Am J Kidney Dis 2002;39:862-71. 